Article

\title{
Greenhouse Effect in the Standard Atmosphere
}

\author{
Boris Michailovich Smirnov * and Dmitri Alexandrovich Zhilyaev * \\ Institute for High Temperatures of Russian Academy Sciences, Izhorskaya 13/19, 127412 Moscow, Russia \\ * Correspondence: bmsmirnov@gmail.com (B.M.S.); zhiliay@gmail.com (D.A.Z.)
}

check for

updates

Citation: Smirnov, B.M.; Zhilyaev, D.A. Greenhouse Effect in the Standard Atmosphere. Foundations 2021, 1, 184-199. https://doi.org/ 10.3390 / foundations 1020014

Academic Editor: Eugene Oks

Received: 4 August 2021

Accepted: 22 September 2021

Published: 27 October 2021

Publisher's Note: MDPI stays neutral with regard to jurisdictional claims in published maps and institutional affiliations.

Copyright: (C) 2021 by the authors. Licensee MDPI, Basel, Switzerland. This article is an open access article distributed under the terms and conditions of the Creative Commons Attribution (CC BY) license (https:// creativecommons.org/licenses/by/ $4.0 /)$.

\begin{abstract}
The "line-by-line" method is used for the evaluation of thermal emission of the standard atmosphere toward the Earth. Accounting for thermodynamic equilibrium of the radiation field with air molecules and considering the atmosphere as a weakly nonuniform layer, we reduce the emission at a given frequency for this layer containing molecules of various types to that of a uniform layer, which is characterized by a certain radiative temperature $T_{\omega}$, an optical thickness $u_{\omega}$ and an opaque factor $g\left(u_{\omega}\right)$. Radiative parameters of molecules are taken from the HITRAN database, and an altitude of cloud location is taken from the energetic balance of the Earth. Within the framework of this model, we calculate the parameters of the greenhouse effect, including the partial radiative fluxes due to different greenhouse components in the frequency range up to $2600 \mathrm{~cm}^{-1}$. In addition, the derivations are determined from the radiative flux from the atmosphere to the Earth over the concentration logarithm of greenhouse components. From this, it follows that the observed rate of growth of the amount of atmospheric carbon dioxide accounts for a contribution of approximately $30 \%$ to the observed increase in the global atmosphere during recent decades. If we assume that the basic part of the greenhouse effect is determined by an increase in the concentration $c\left(\mathrm{H}_{2} \mathrm{O}\right)$ of water atmospheric molecules, it is approximately $d \ln c\left(\mathrm{H}_{2} \mathrm{O} / d t\right)=0.003 \mathrm{yr}^{-1}$. This corresponds to an increase in the average moisture of the atmosphere of $0.2 \% / \mathrm{yr}$.
\end{abstract}

Keywords: line-by-line; greenhouse effect; radiative fluxes; thermal emission

\section{Introduction}

The goal of this paper is to evaluate the radiative fluxes for the greenhouse effect in the atmosphere. This evaluation is based on a developed algorithm formulated in [1]. The used model includes the following features.

1. The "line-by-line" model [2,3] is the basis of these evaluations, and integral radiative fluxes follow from these partial fluxes.

2. The model includes three basic greenhouse components, namely, $\mathrm{H}_{2} \mathrm{O}$ molecules, $\mathrm{CO}_{2}$ molecules and liquid water microdroplets, as the basic condensed phase in the atmosphere. In addition, trace components, such as $\mathrm{CH}_{4}$ molecules and $\mathrm{N}_{2} \mathrm{O}$ molecules, may be included in this scheme.

3. The model of standard atmosphere [4] is the basis of evaluations. In particular, the global temperature (the average temperature of the Earth's surface) is taken as $T_{E}=288 \mathrm{~K}$, and its decrease with altitude $h$ is $d T / d h=-6.5 \mathrm{~K} / \mathrm{km}$. This model provides the altitude distribution for the number densities of atmospheric molecules. The model of standard atmosphere implies that atmospheric parameters depend only on the altitude.

4. Along with the local thermodynamic equilibrium for atmospheric components, this equilibrium takes place between the radiation field and atmospheric air.

5. Parameters of radiative transitions of greenhouse molecules are taken from the HITRAN data bank [5-7]; therefore, we use the formalism for the rates of molecular radiative processes of this data bank [8].

6. The energetic balance of the Earth and its atmosphere is taken into account. According to this balance, radiative fluxes toward the Earth and outside are determined by different atmospheric regions and are separated, i.e., the radiative fluxes to the Earth 
that are connected with its temperatures do not depend on processes in high layers of the troposphere.

7. Basic greenhouse components are separated so that clouds are located starting from a certain altitude, and they are characterized by a sharp boundary. Radiation from greenhouse molecules is created in the gap between the Earth's surface and clouds.

Differences between these evaluations and those of [1] are twofold. First, the computer code presented in our paper does not separate frequencies in different ranges; this code relates to the total range of frequencies. Second, evaluations [1] are restricted by frequencies below $1200 \mathrm{~cm}^{-1}$. Since the absorption in an additional frequency range is determined by water molecules, new evaluations may change the emission, due to water molecules. Of course, we account for this in our analysis for a contemporary understanding of atmospheric physics and processes in the atmosphere [2,3,9-22].

\section{Model of Atmospheric Emission to the Earth}

Thus, we evaluate the radiative fluxes on the basis of the algorithm, which is formulated in the introduction section. The character of radiative processes is given in Figure 1. Correspondingly, according to the model under consideration, we have for the radiative flux $J_{\omega}$ at a given frequency $\omega$ the following:

$$
J_{\omega}=I_{\omega}\left(T_{\omega}\right) g\left(u_{\omega}\right)+I_{\omega}\left(T_{c l}\right)\left[1-g\left(u_{\omega}\right)\right]
$$

where $I_{\omega}(T)$ is the radiative flux of a blackbody with a temperature $T$ at this frequency that is given by the Planck formula as follows [23,24]:

$$
I_{\omega}(T)=\frac{\hbar \omega^{3}}{4 \pi^{2} c^{2}\left[\exp \left(\frac{\hbar \omega}{T}\right)-1\right]},
$$

and the opaque factor $g\left(u_{\omega}\right)$ of a uniform gaseous layer is given by the following [25,26]:

$$
g\left(u_{\omega}\right)=2 \int_{0}^{1} \cos \theta d \cos \theta\left[1-\exp \left(-\frac{u_{\omega}}{\cos \theta}\right)\right],
$$

Formula (3) takes into account the thermodynamic equilibrium of air molecules of the atmosphere with its optically active molecules, water microdroplets of clouds, and the radiation field.

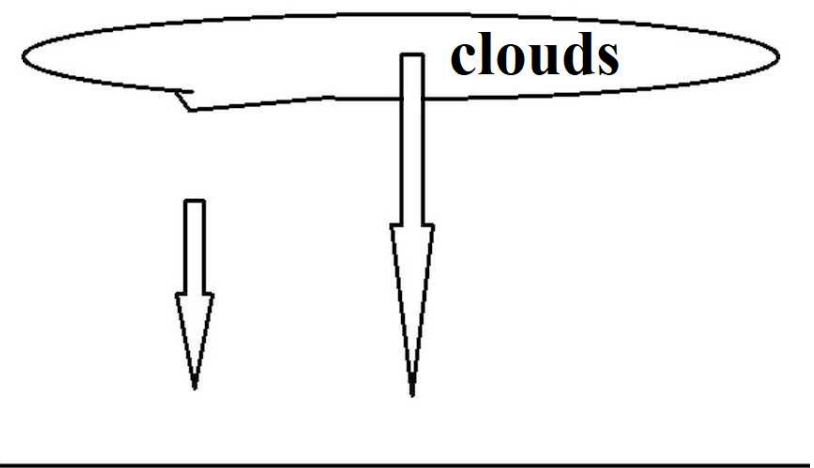

\section{Earth}

Figure 1. Character of emission of the atmosphere toward the Earth, according to which the radiative flux consists of those from clouds and atmospheric molecules located in the gap between the Earth and clouds. 
We thus consider the radiating atmosphere as a shell of the Earth, whose thickness is small compared with the radius of the Earth. Hence, the radiating atmosphere is a weakly nonuniform gaseous layer [27]. One can reduce a radiating weakly nonuniform layer that contains optically active molecules to an effective uniform layer by introducing the effective temperature of radiation or the radiative temperature $T_{\omega}[28,29]$. In addition, due to thermodynamic equilibrium in the atmosphere, the emission of clouds is characterized by the cloud + temperature $T_{c l}$ or the temperature of the cloud boundary because of its sharp structure.

Formula (1) contains parameters that are expressed through the optical thickness $u_{\omega}$ of the radiated atmospheric layer, which in turn is connected with the optical parameters of optically active molecules, which are located in atmospheric air. There are three greenhouse parameters of the radiated atmospheric layer, namely, $\mathrm{H}_{2} \mathrm{O}$ molecules, $\mathrm{CO}_{2}$ molecules, and clouds consisting mostly of water microdroplets. Correspondingly, the optical thickness of the atmospheric gap located between the Earth and clouds is given by the following [1]:

$$
u_{\omega}\left(h_{\omega}\right)=\sigma_{\omega}\left(\mathrm{H}_{2} \mathrm{O}\right) N\left(\mathrm{H}_{2} \mathrm{O}\right) \lambda\left[1-\exp \left(-\frac{h_{\omega}}{\lambda}\right)\right]+\sigma_{\omega}\left(\mathrm{CO}_{2}\right) N\left(\mathrm{CO}_{2}\right) \Lambda\left[1-\exp \left(-\frac{h_{\omega}}{\Lambda}\right)\right],
$$

where the number densities of water molecules and carbon dioxide molecules are determined by the following formulas:

$$
\begin{aligned}
& N\left(H_{2} \mathrm{O}\right)=N_{w} \exp \left(-\frac{h}{\lambda}\right), N_{w}=3.4 \times 10^{17} \mathrm{~cm}^{-3}, \lambda=2.0 \mathrm{~km} \\
& N\left(\mathrm{CO}_{2}\right)=N_{c} \exp \left(-\frac{h}{\Lambda}\right), N_{c}=1.1 \times 10^{16} \mathrm{~cm}^{-3}, \Lambda=10 \mathrm{~km}
\end{aligned}
$$

We use here the data of the model of standard atmosphere [4] and measured data on the basis of the NASA programs, which are analyzed in [30]. In addition, the equation for the effective altitude $h_{\omega}$ at a given frequency $\omega$ has the following form [1]:

$$
u_{\omega}\left(h_{\omega}\right)=\frac{u_{\omega}\left(h_{c l}\right)}{2 \exp \left(-u_{\omega}\left(h_{c l}\right)+1.5 u_{\omega}\left(h_{c l}\right)\right)}
$$

Within the framework of the model of standard atmosphere, the radiative temperature $T_{\omega}$ for a given frequency follows from the given relation:

$$
T_{\omega}=T_{E}-h_{\omega} \frac{d T}{d h}
$$

where the global temperature equals $T_{E}=288 \mathrm{~K}$ for the contemporary standard atmosphere, and its gradient is $d T / d h=6.5 \mathrm{~K} / \mathrm{km}$.

Formula (4) includes the absorption cross section $\sigma_{\omega}$ for molecules of a given sort, which is a sum of the cross sections for individual spectral lines due to this component, according to the following formula:

$$
\sigma_{\omega}=\sum_{j} \frac{S_{j} v_{j}}{2 \pi\left[\left(\omega-\omega_{j}\right)^{2}+\left(v_{j} / 2\right)^{2}\right]}
$$

As is seen, for each radiative transition, this formula contains three parameters, namely, the transition intensity $S_{j}$, the frequency $\omega_{j}$ at the line center, and the width of this spectral line $v_{j}$. We take these parameters from the HITRAN data bank [5-7], and these parameters allow one to determine the absorption cross section at a given frequency. In addition, for air pressures under consideration which are of the order of atmospheric one, the following criterion is fulfilled:

$$
\Delta \omega \gg v_{j},
$$


where $\Delta \omega$ is a typical difference of frequencies for centers of neighboring spectral lines.

Note that, according to the Wien law [31], the maximum flux of photons for a blackbody corresponds to the wavelength $\lambda$ as follows:

$$
\lambda_{\max } T=0.3 \mathrm{~cm} \cdot \mathrm{K}
$$

From this, it follows that a typical wavelength of atmospheric radiation is $\lambda \sim 10 \mu \mathrm{m}$. Therefore, below, we are restricted by frequencies $\omega<2600 \mathrm{~cm}^{-1}$.

In this evaluation, we are guided by strong spectral lines such that at the centers of these lines, the optical thickness satisfies the relation $u_{\omega}>1$. In accordance with typical parameters of spectral lines due to water and carbon dioxide molecules, one can select from the HITRAN data bank radiative transitions for these molecules whose intensities satisfy the following relation:

$$
S_{j}\left(\mathrm{H}_{2} \mathrm{O}\right) \gg 1 \times 10^{-24} \mathrm{~cm}, S_{j}\left(\mathrm{CO}_{2}\right) \gg 2 \times 10^{-23} \mathrm{~cm}
$$

The problem in the evaluation of the radiative flux of the atmosphere is determining the parameters of clouds. In contrast to the number densities of optically active molecules, which are given by Formula (4), analogous information for clouds is absent. Indeed, clouds exist over a given surface point during a restricted time, and their distribution over altitudes has a random character. Within the framework of the model under consideration, we use one parameter of clouds, namely, the altitude $h_{c l}$, which determines the radiation of clouds, or the radiative temperature of clouds $T_{c l}$, which follows from the given equation below:

$$
T_{c l}=T_{E}-\frac{d T}{d h} h_{c l}
$$

where the global temperature is $T_{E}=288 \mathrm{~K}$, and the temperature gradient is $d T / d h=6.5 \mathrm{~K} / \mathrm{km}$.

One can determine the cloud parameters of this model by using the energetic balance of the Earth and atmosphere. The energetic balance includes the radiative flux $J_{\downarrow}$ from the atmosphere toward the Earth. The energetic balance and this radiative flux follows from different sources, which are presented in Table 1 . The total radiative flux from the atmosphere to the Earth is given by the following:

$$
J_{\downarrow} \equiv \int J_{\omega} d \omega
$$

This analysis is used below for calculating the partial radiative fluxes from the atmosphere to the Earth.

Table 1. Values of the total radiative flux from the atmosphere to the Earth as it follows from different versions of the energetic balance for the Earth and its atmosphere with references that contain a certain version of the sources. The altitude $h_{c l}$ of the cloud boundary and the temperature $T_{c l}$ of the cloud emission relate to the corresponding version of Earth's energetic balance.

\begin{tabular}{ccccccc}
\hline Number & $\mathbf{1}$ & $\mathbf{2}$ & $\mathbf{3}$ & $\mathbf{4}$ & $\mathbf{5}$ & Average \\
\hline$J_{\downarrow}, \mathrm{W} / \mathrm{m}^{2}$ & 327 & 327 & 333 & 346 & 342 & $335 \pm 7$ \\
Reference & {$[21,32-34]$} & {$[18,35-40]$} & {$[41-44]$} & {$[45]$} & {$[46]$} & - \\
$h_{c l}, \mathrm{~km}$ & 5.6 & 5.6 & 4.8 & 3.2 & 3.7 & $4.6 \pm 0.7$ \\
$T_{c l}, K$ & 252 & 252 & 257 & 267 & 264 & $258 \pm 6$ \\
\hline
\end{tabular}

\section{Radiative Fluxes from the Standard Atmosphere}

Evaluations of the radiative fluxes from the atmosphere to the Earth are based on the above algorithm [1]. In the previous analysis, the frequency range was separated over several ranges, and evaluations were fulfilled in each range independently. In this case, within the framework of a general computer code, one can make calculations in the total 
range of frequencies that determine the radiative flux. Let us choose the effective range of flux evaluations. If the Earth's surface with the temperature of the standard atmosphere $T_{E}=288 \mathrm{~K}$ emits as a blackbody, the radiative flux at frequencies above $1300 \mathrm{~cm}^{-1}$ is $10 \%$ of the total radiative flux, the radiative flux at frequencies above $2000 \mathrm{~cm}^{-1}$ is $1 \%$ of the total radiative flux, and the radiative flux at frequencies above $2600 \mathrm{~cm}^{-1}$ is $0.1 \%$ of the total radiative flux. In previous evaluations [1], calculations were made for frequencies below $1260 \mathrm{~cm}^{-1}$, accounting for the radiation of molecules $\mathrm{CO}_{2}, \mathrm{CH}_{4}$ and $\mathrm{N}_{2} \mathrm{O}$ at larger frequencies. We are now restricted by the frequency range below $2600 \mathrm{~cm}^{-1}$.

By analogy with evaluations [1], in subsequent calculations, we use information about radiative transitions from the HITRAN data bank. Figure 2 contains the frequency dependence for the optical thickness of the atmospheric layer between the Earth's surface and clouds, which is determined by optically active atmospheric molecules in the infrared spectrum range. As it follows from this Figure, optical parameters of the atmosphere as a frequency function have a line character. One can determine from this the radiative temperature of molecules located in the atmospheric gap between the Earth and clouds, and its frequency dependence is presented in Figure 3.

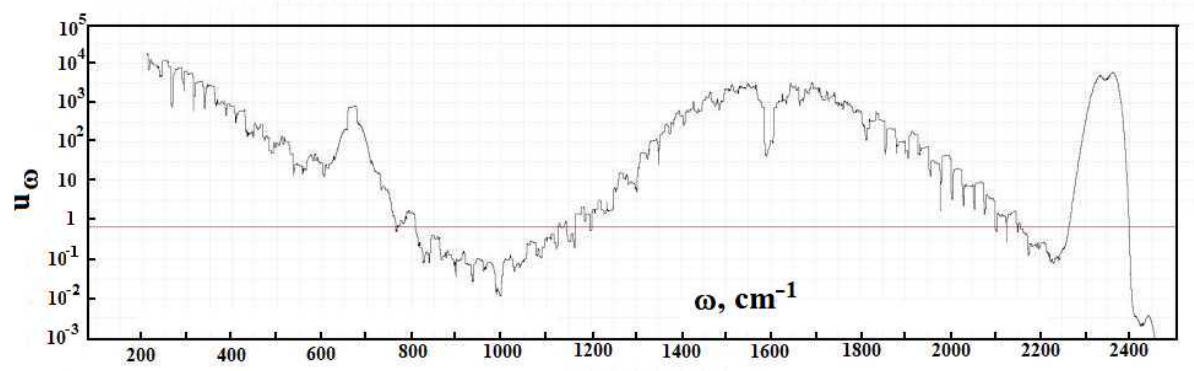

Figure 2. Optical thickness $u_{\omega}$ of the atmospheric gap between the Earth and clouds due to optically active atmospheric molecules. The solid curve corresponds to $u_{\omega}=2 / 3$ and the cloud altitude is $h_{c l}=4.6 \mathrm{~km}$.

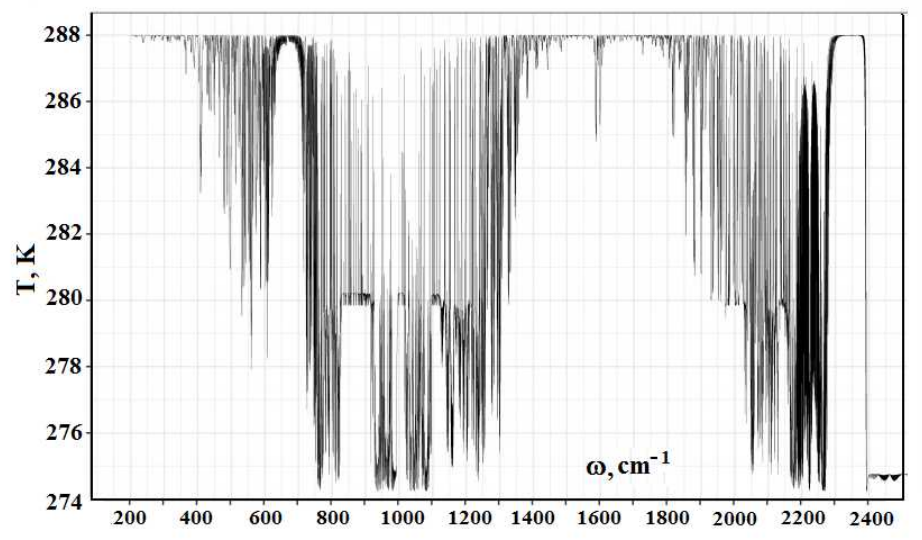

Figure 3. Radiative temperature $T_{\omega}$ due to atmospheric molecules located in the gap between the Earth's surface and clouds, whose boundary is located at the altitude $h_{c l}=4.6 \mathrm{~km}$.

Figure 4 contains values of radiative temperatures, given in Figure 3, which are averaged over ranges of $20 \mathrm{~cm}^{-1}$ width. This averaging is made over the frequency range of the width of $10 \mathrm{~cm}^{-1}$ below and above the frequency under consideration. 


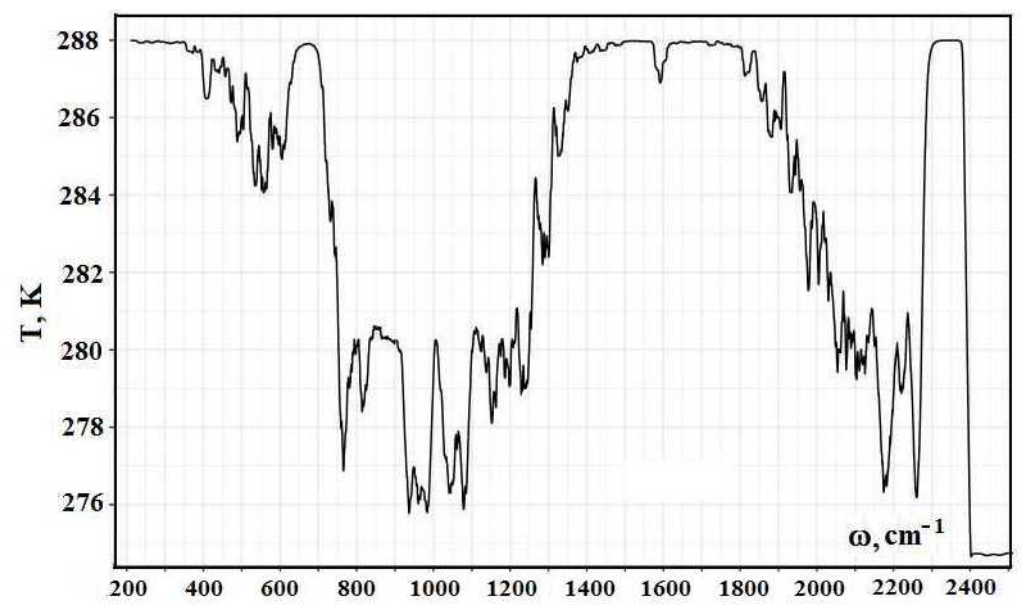

Figure 4. Averaged over a range of $20 \mathrm{~cm}^{-1}$, radiative temperatures $T_{\omega}$, which are determined by emission of atmospheric molecules, which are located in the gap between the Earth's surface and clouds. The cloud boundary is found at the altitude $h_{c l}=4.6 \mathrm{~km}$.

The opaque factor $g\left(u_{\omega}\right)$ is determined by Formula (3), and its frequency dependence is given in Figure 5. The averaged value of the opaque factor is given in Figure 6. The averaging is made over the frequency range of $20 \mathrm{~cm}^{-1}$ by analogy with that for the radiative temperature.

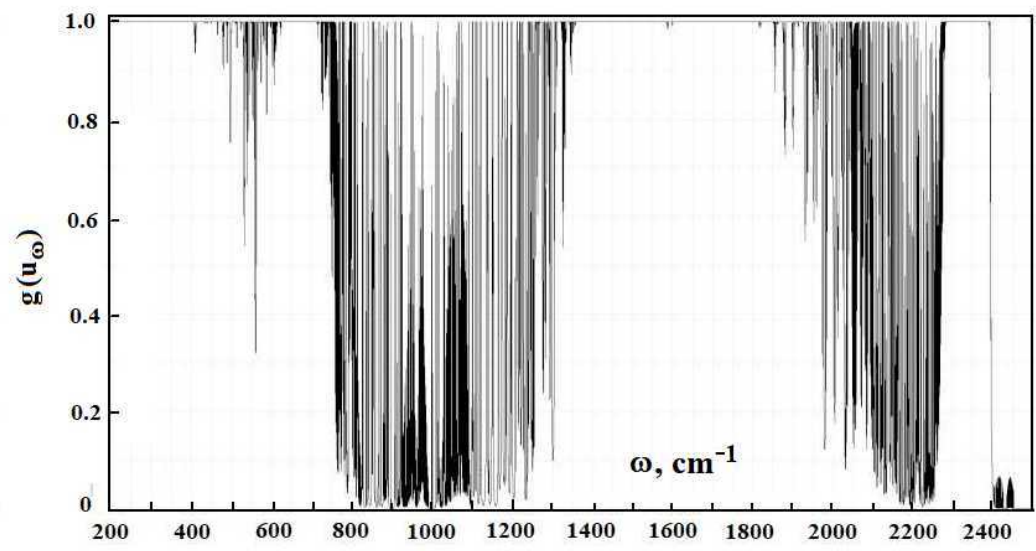

Figure 5. Opaque factor $g\left(u_{\omega}\right)$ due to absorption of atmospheric molecules in the gap between the Earth's surface and clouds if the cloud boundary is located at the altitude $h_{c l}=4.6 \mathrm{~km}$. The model is shown, where the atmosphere is transparent in the frequency range between $780 \mathrm{~cm}^{-1}$ and $1250 \mathrm{~cm}^{-1}$.

The opaque factor characterizes the part of the radiative flux that is emitted by the Earth's surface and attains the clouds. Figure 7 contains the radiative flux $I_{\omega}\left(T_{E}\right)$ that is emitted by the Earth as well as the radiative flux $\overline{g\left(u_{\omega}\right)} I_{\omega}\left(T_{E}\right)$ at a given frequency, which reaches the clouds for the model of standard atmosphere. We have also the average radiative flux, which is emitted by the Earth and reaches the cloud boundary as follows:

$$
J_{\uparrow}=\int \overline{g\left(u_{\omega}\right)} I_{\omega}\left(T_{E}\right) d \omega
$$

Taking $T_{E}=288 \mathrm{~K}$ on the basis of the model of standard atmosphere, we obtain the following:

$$
J_{E}=\int I_{\omega}\left(T_{E}\right) d \omega=390 \mathrm{~W} / \mathrm{m}^{2}
$$


in accordance with the energetic balance of the Earth, and $J_{\uparrow}=120 \mathrm{~W} / \mathrm{m}^{2}$. As is seen, a part of the thermal radiative flux that passes through the atmospheric layer below clouds and reaches the clouds is approximately $30 \%$ of the emitted radiative flux.

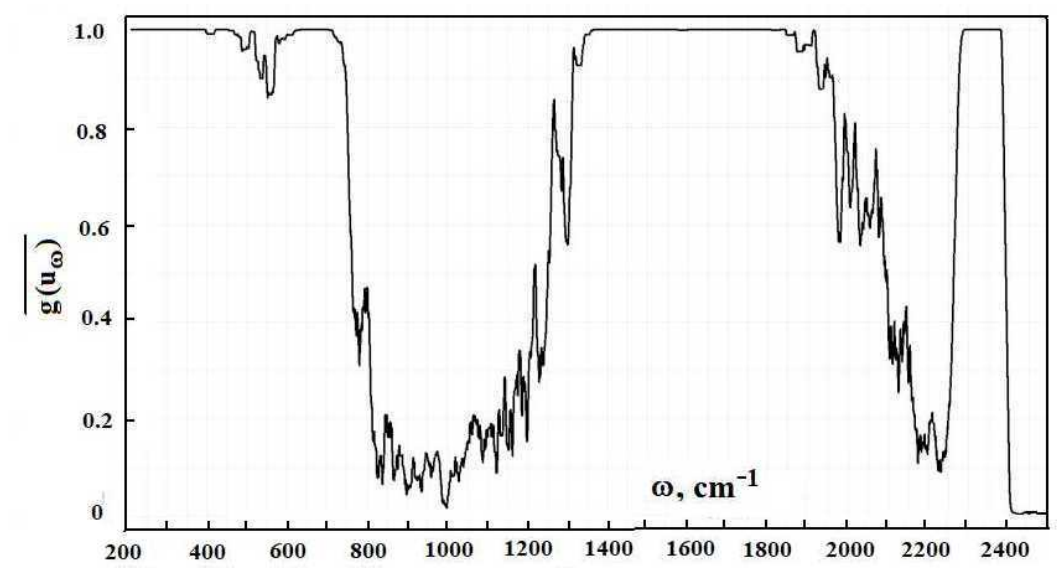

Figure 6. The averaged opaque factor $\overline{g\left(u_{\omega}\right)}$ over a frequency range of $20 \mathrm{~cm}^{-1}$ for the absorption of atmospheric molecules located in the gap between the Earth's surface and clouds. The cloud boundary is located at the altitude $h_{c l}=4.6 \mathrm{~km}$.

From Formulas (1) and (13), one can determine the radiative flux from the atmosphere to the Earth's surface due to atmospheric molecules and clouds; this flux depends on the cloud temperature $T_{c l}$ or the boundary altitude $h_{c l}$ for clouds. This dependence is represented in Figure 8. In addition, these parameters are given in Table 1 for different versions of the energetic balance of the Earth and its atmosphere.

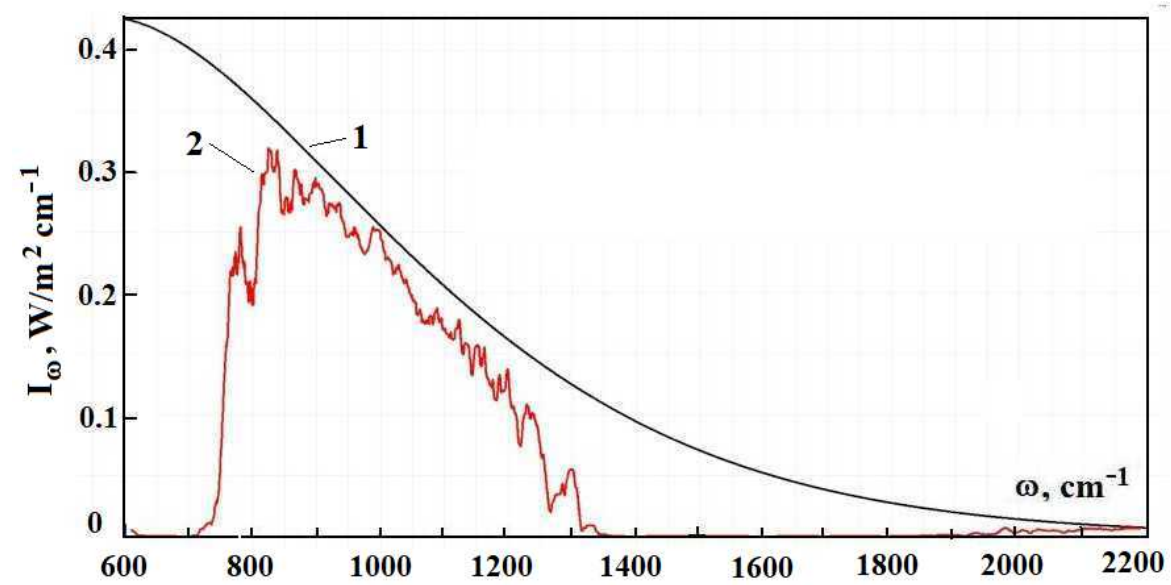

Figure 7. The frequency dependence for the radiative flux $I_{\omega}\left(T_{E}\right)$ from the Earth's surface (1) and its part $\overline{g\left(u_{\omega}\right)} I_{\omega}\left(T_{E}\right)$, which attains the boundary of clouds.

In previous evaluations [1], only data of the first source of Table 1 were used, whereas now we are based on a variety of these values. Because parameters of the Earth's energetic balance are different for these sources, this difference characterizes also the error in the final results. Note that the connection between the effective altitude $h_{c l}$ of the cloud boundary and the cloud temperature $T_{c l}$ is given by Formula (12).

A cursory glance at the emission parameters of the atmosphere according to Figures 2, 3 and 5 exhibits that the spectrum of atmospheric radiation consists of separate spectral lines, in contrast to climatological models with a smooth empiric frequency functions, which approximate the atmospheric spectrum. In addition, climatological models do not take into account the thermodynamics of the atmosphere and radiation field. 
Therefore, computer codes of climatology are not reliable in the evaluation of the radiative parameters of the atmosphere.

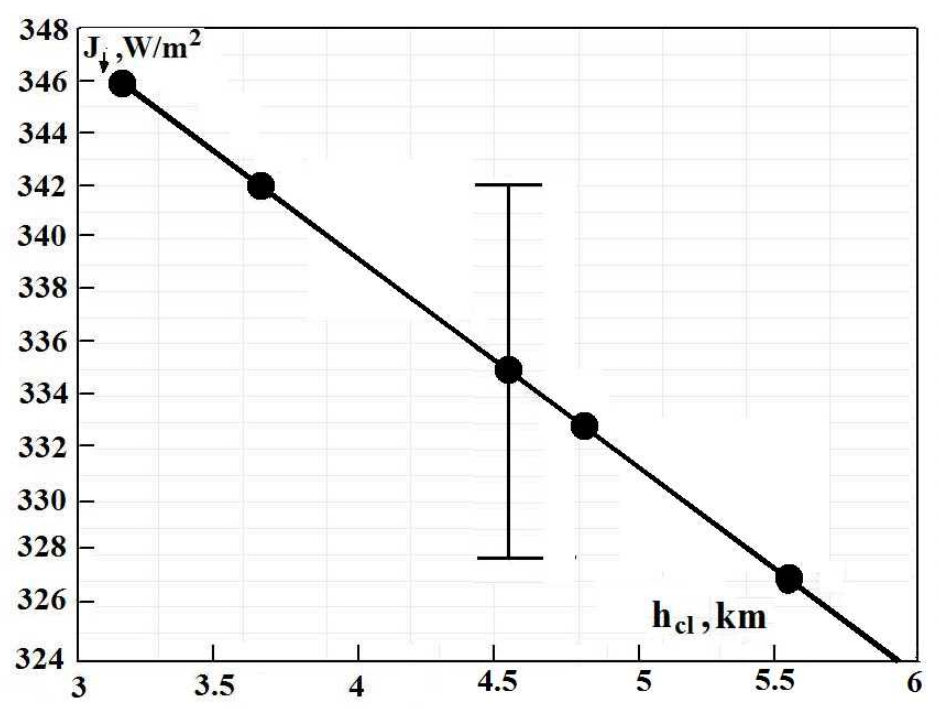

Figure 8. Dependence of the total radiative flux from the atmosphere to the Earth $J_{\downarrow}$ on the altitude of the cloud boundary $h_{c l}$. The average value of the radiative flux toward the Earth is marked.

One can divide the radiative flux $J_{\omega}$ from the atmosphere to the Earth in parts that are created by various components of the radiated atmosphere. For example, the partial radiative flux $J_{\omega}\left(\mathrm{CO}_{2}\right)$, which is determined by $\mathrm{CO}_{2}$ molecules, is given by the following formula:

$$
J_{\omega}\left(\mathrm{CO}_{2}\right)=J_{\omega} \frac{k_{\omega}\left(\mathrm{CO}_{2}\right)}{k_{\omega}},
$$

where $J_{\omega}$ is the total radiative flux, $k_{\omega}\left(\mathrm{CO}_{2}\right)$ is the absorption coefficient due to $\mathrm{CO}_{2}$ molecules, and $k_{\omega}$ is the total absorption coefficient at a given frequency. These absorption coefficients are taken at the radiative temperature $T_{\omega}$. Integrating the partial radiative flux as a frequency function over frequencies, one can determine the total radiative flux from the atmosphere to the Earth due to this component. Table 2 contains values of the total radiative flux from the atmosphere due to each greenhouse component.

Table 2. Radiative fluxes in $\mathrm{W} / \mathrm{m}^{2}$ for indicated frequency ranges and the total radiative flux due to a given component. Results of evaluations [1] are given in square parentheses.

\begin{tabular}{ccccc}
\hline Component & $\boldsymbol{\omega}<\mathbf{8 0 0} \mathbf{~ m}^{-\mathbf{1}}$ & $\begin{array}{c}\mathbf{1 2 5 0} \mathbf{~ m}^{-\mathbf{1}} \mathbf{c} \\
\boldsymbol{\omega}>\mathbf{8 0 0} \mathbf{c m}^{-\mathbf{1}}\end{array}$ & $\boldsymbol{\omega}>\mathbf{1 2 5 0} \mathbf{c m}^{-\mathbf{1}}$ & Sum \\
\hline $\mathrm{H}_{2} \mathrm{O}$-molecules & 163 & 13 & 39 & $(215 \pm 2)[166]$ \\
$\mathrm{H}_{2} \mathrm{O}$-droplets & 8 & 52 & 1 & $(61 \pm 7)[96]$ \\
water in total & 171 & 65 & 40 & $(276 \pm 10)[262]$ \\
$\mathrm{CO}_{2}$-molecules & 53 & 2 & 1 & $(56 \pm 1)[60]$ \\
$\mathrm{CH}_{4}$-molecules & 0 & 1 & 1 & $2[4]$ \\
$\mathrm{N}_{2} \mathrm{O}$-molecules & 0 & 0 & 1 & $1[3]$ \\
\hline
\end{tabular}

One can compare the results for radiative fluxes of these evaluations given in Table 2 and previous ones [1]. The basic difference is that the basic part of the emission, according to [1], is taken from the frequency range $\omega<800 \mathrm{~cm}^{-1}$; in the other frequency range $\omega>800 \mathrm{~cm}^{-1}$, which gives the contribution approximately $10 \%$ to the radiative flux, the emission of water molecules is ignored. In these evaluations, the HITRAN bank data are included up to $\omega=2600 \mathrm{~cm}^{-1}$. As a result, a part of the emission transfers from clouds to water molecules. We also note that average radiative fluxes given in Table 2, according to 
evaluations [1], refer to the total radiative flux $J_{\downarrow}=327 \mathrm{~W} / \mathrm{m}^{2}$ from the atmosphere toward the Earth, whereas now, we are guided by this flux $J_{\downarrow}=(335 \pm 7) \mathrm{W} / \mathrm{m}^{2}$; the results of Table 2 correspond to the total flux.

In addition, Figure 9 contains radiative fluxes due to individual greenhouse components. The frequency range is separated into two parts with the boundary of $800 \mathrm{~cm}^{-1}$. One can evaluate separately the emission of trace greenhouse components, which are $\mathrm{CH}_{4}$ and $\mathrm{N}_{2} \mathrm{O}$ molecules. The number density of these molecules as an altitude function is analogous to formula (5) for $\mathrm{CO}_{2}$ molecules and is given by the following formulas:

$$
N\left(\mathrm{CH}_{4}\right)=N_{m} \exp \left(-\frac{h}{\Lambda}\right), N_{m}=3.5 \times 10^{13} \mathrm{~cm}^{-3}, N\left(N_{2} \mathrm{O}\right)=N_{n} \exp \left(-\frac{h}{\Lambda}\right), N_{n}=7.5 \times 10^{12} \mathrm{~cm}^{-3} \Lambda=10 \mathrm{~km}
$$

The number densities of these molecules at the Earth's surface are taken from $[47,48]$. The absorption band for the $\mathrm{CH}_{4}$ molecule is $(1240-1360) \mathrm{cm}^{-1}$, the absorption bands for $\mathrm{N}_{2} \mathrm{O}$ molecule are placed in the frequency ranges $(1250-1310) \mathrm{cm}^{-1}$ and $(2180-2260) \mathrm{cm}^{-1}$. Figure 10 contains the partial optical thickness as a frequency function in the above absorption bands, due to individual greenhouse components, which include the above trace components and water molecules.

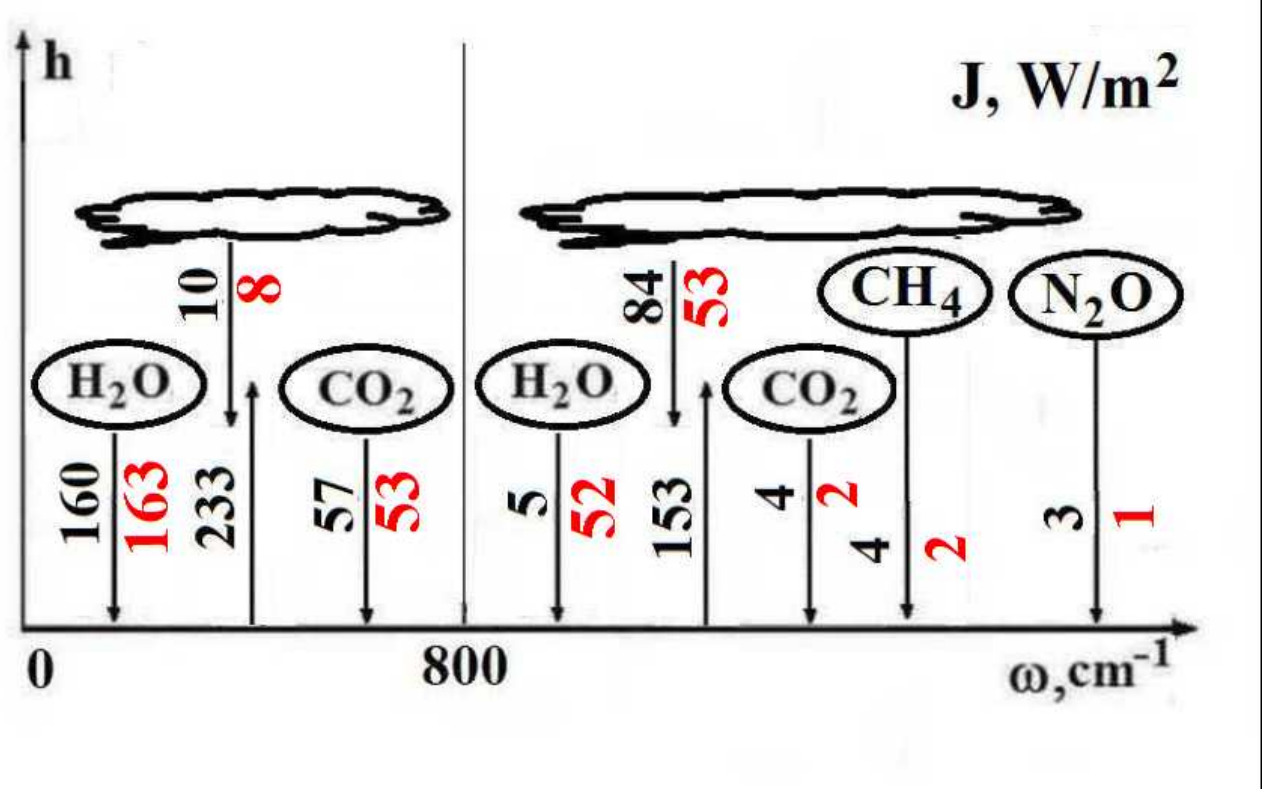

Figure 9. Radiative fluxes $J_{E}$ from the Earth's surface for the model of standard atmosphere, and also fluxes from clouds and to indicated molecular components, where radiation attains the Earth's surface. A molecular component is indicated inside an ellipse; average values of the fluxes are expressed in $\mathrm{W} / \mathrm{m}^{2}$. Data of [1] are represented in black, and the results of these evaluations are given in red.

As it is seen, the optical thickness due to trace gases is not large and is screened by absorption of water molecules. Because we ignored in [1] the absorption of water molecules at the wing $\omega>1200 \mathrm{~cm}^{-1}$ of atmospheric thermal emission, evaluations [1] contain heightened values of radiative fluxes due to trace gases, as it follows from the data of Figure 9 and Table 2.

It should be noted that we exclude the ozone emission from the tropospheric radiation toward the Earth since the concentration of ozone molecules in the troposphere usually does not exceed $10^{12} \mathrm{~cm}^{-3}$. Therefore, the optical thickness of the troposphere in the gap between the Earth's surface and clouds is small. The concentration of ozone molecules in the stratosphere is larger, but the stratospheric radiation does not reach the Earth because it is absorbed by clouds. Hence, we ignore the radiation of ozone molecules in the atmosphere. 


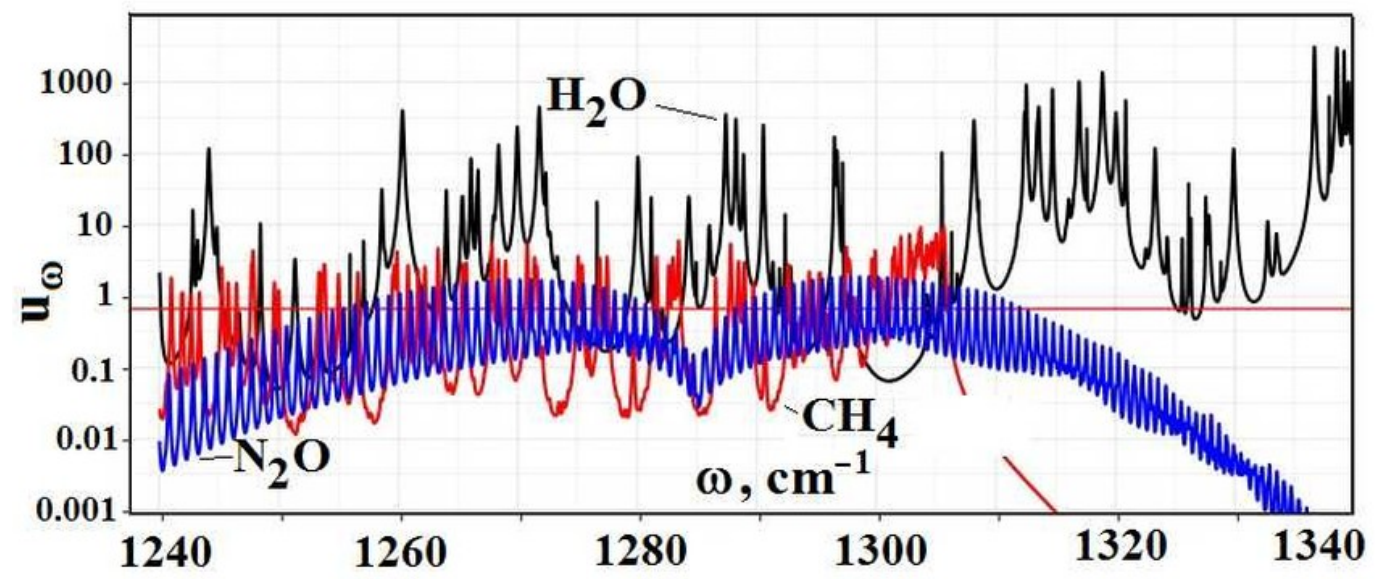

Figure 10. Optical thickness $u_{\omega}$ of the atmospheric gap between the Earth and clouds due to optically active atmospheric molecules $\mathrm{CH}_{4}, \mathrm{~N}_{2} \mathrm{O}$ and $\mathrm{H}_{2} \mathrm{O}$ in the absorption bands of trace gases.

\section{Emission of Atmosphere with a Varied Composition}

The code under consideration allows one to analyze variations in the radiative fluxes as a result of the change in the atmosphere composition. We start this analysis from the standard case, where the concentration of $\mathrm{CO}_{2}$ molecules is doubled. This leads to the change in the global temperature that is named "Equilibrium Climate Sensitivity" [49]. Note that this operation implies that optically active gases have a uniform distribution over the globe that corresponds to the average altitude distribution. This criterion is fulfilled more or less for $\mathrm{CO}_{2}$ molecules, and the uniform distribution is violated for $\mathrm{H}_{2} \mathrm{O}$ molecules.

In this consideration, we take into account three basic greenhouse components, namely, $\mathrm{CO}_{2}$ molecules, $\mathrm{H}_{2} \mathrm{O}$ molecules, and water microdroplets of clouds. Table 3 contains the distribution over the spectrum for the change in radiative fluxes due to a given component as a result of doubling the concentration of $\mathrm{CO}_{2}$ molecules. Quantities $\Delta_{c}, \Delta_{w}, \Delta_{d}$ of this table are the changes in the radiative fluxes to the Earth due to $\mathrm{CO}_{2}$ molecules, $\mathrm{H}_{2} \mathrm{O}$ molecules, and water microdroplets of clouds, correspondingly, according to the following relations:

$\Delta_{c}=\int\left[J_{\omega}^{\prime}\left(\mathrm{CO}_{2}\right)-J_{\omega}\left(\mathrm{CO}_{2}\right)\right] d \omega, \Delta_{w}=\int\left[J_{\omega}^{\prime}\left(\mathrm{H}_{2} \mathrm{O}\right)-J_{\omega}\left(\mathrm{H}_{2} \mathrm{O}\right)\right] d \omega, \Delta_{d}=\int\left[J_{\omega}^{\prime}(\right.$ drop $)-J_{\omega}($ drop $\left.)\right] d \omega$,

where $J_{\omega}(A)$ is the radiative flux due to an indicated component $A$ at the current concentration of $\mathrm{CO}_{2}$ molecules, and $J_{\omega}^{\prime}$ is the radiative flux of this component at the doubling concentration of $\mathrm{CO}_{2}$ molecules. The change in the total radiative flux $\Delta$ is introduced as follows:

$$
\Delta=\Delta_{c}+\Delta_{w}+\Delta_{d}
$$

It is evident that the change in radiative fluxes of components as well as the total change in the radiative flux from the atmosphere to the Earth takes place only in spectrum ranges where $\mathrm{CO}_{2}$ molecules absorb. In addition, the basic change in the radiative flux as a result of the concentration change for some optically active components takes place in the frequency range where the optical thickness is of the order of one. The red line $u_{\omega}=2 / 3$ in Figures 2, 10, and 11 separates the optical thicknesses, with large ones above this line and low ones below it. Comparing the data of Table 3 and Figure 11, one can conclude that the main contribution to the change in the radiative flux follows from a frequency range where $u_{\omega} \sim 1$. Next, changes in radiative fluxes resulted from the variation in the concentration of $\mathrm{CO}_{2}$ molecules are nearby, according to these calculations and evaluations [1], because the absorption of $\mathrm{CO}_{2}$ molecules is absent in the added frequency range $1200 \mathrm{~cm}^{-1}<\omega<2600 \mathrm{~cm}^{-1}$. On the contrary, in the case of the change in the concentration of water molecules, the change in the total radiative flux differs by several times under identical conditions. 
Table 3. Variations in radiative fluxes for the standard atmosphere as a result of doubling of the $\mathrm{CO}_{2}$ concentration in an indicated spectrum range of $\mathrm{CO}_{2}$ molecules. The frequency ranges $\Delta \omega$ are given in $\mathrm{cm}^{-1}$, and radiative fluxes are expressed in $\mathrm{W} / \mathrm{m}^{2}$. Results of calculations [1] are given in parentheses.

\begin{tabular}{ccccc}
\hline Frequency Range, $\mathbf{c m}^{-\mathbf{1}}$ & $\boldsymbol{\Delta}_{\boldsymbol{c}}$ & $\boldsymbol{\Delta}_{\boldsymbol{w}}$ & $\boldsymbol{\Delta}_{\boldsymbol{d}}$ & $\boldsymbol{\Delta}$ \\
\hline $580-600$ & 0.70 & -0.60 & -0.05 & $0.05(0.03)$ \\
$600-620$ & 0.91 & -0.75 & -0.05 & $0.11(0.04)$ \\
$620-640$ & 0.75 & -0.71 & 0 & $0.04(0.02)$ \\
$640-660$ & 0.23 & -0.22 & 0 & $0.01(0.01)$ \\
$660-680$ & 0.08 & -0.08 & 0 & $0(0)$ \\
$680-700$ & 0.27 & -0.26 & 0 & $0.01(0.01)$ \\
$700-720$ & 0.38 & -0.32 & 0 & $0.06(0.06)$ \\
$720-740$ & 0.56 & -0.20 & -0.12 & $0.24(0.20)$ \\
$740-760$ & 1.03 & -0.42 & -0.37 & $0.24(0.29)$ \\
$760-780$ & 0.65 & -0.02 & -0.45 & $0.18(0.14)$ \\
$780-800$ & 0.25 & 0 & -0.17 & $0.08(0.06)$ \\
$800-850$ & 0.18 & 0.01 & -0.15 & $0.04(0.04)$ \\
$900-950$ & 0.20 & 0 & -0.15 & $0.05(0.04)$ \\
$950-1000$ & 0.35 & 0 & -0.25 & $0.10(0.22)$ \\
$1000-1050$ & 0.18 & 0 & -0.12 & $0.06(0.05)$ \\
$1050-1100$ & 0.45 & 0 & -0.31 & 0.14 \\
$2250-2400$ & 0.02 & 0 & -0.01 & 0.01 \\
\hline total & $7.19(7.24)$ & $-3.57(-3.02)$ & $-2.20(-2.90)$ & $1.42(1.32)$ \\
\hline
\end{tabular}

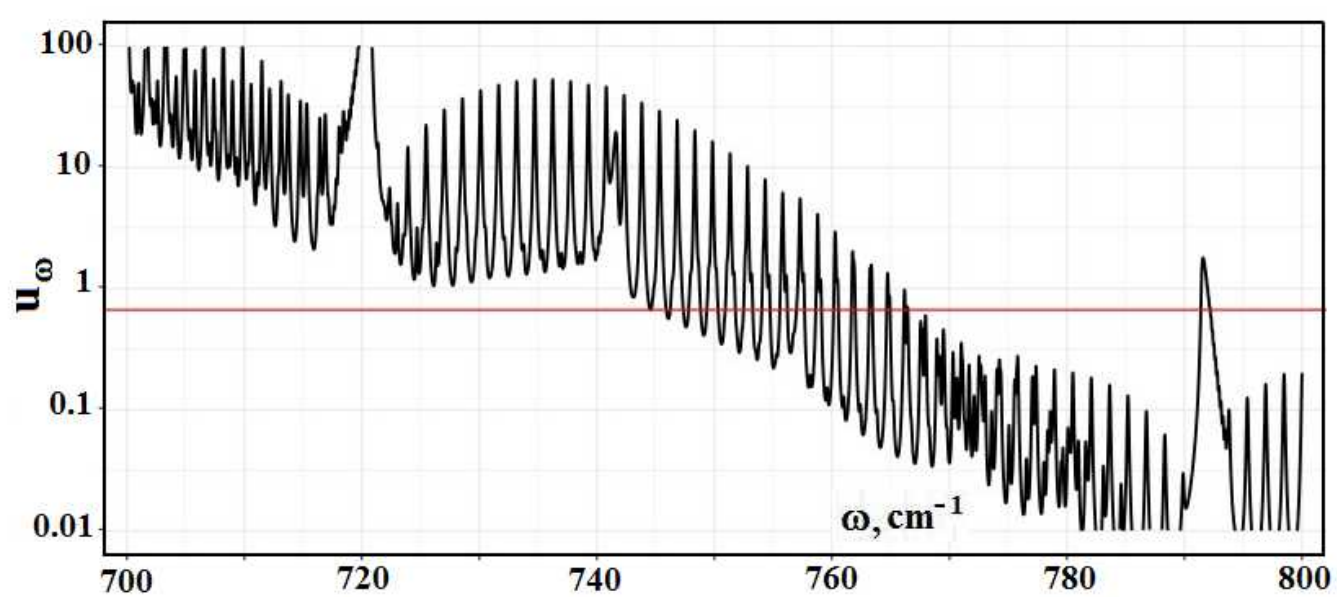

Figure 11. Optical thickness $u_{\omega}$ of the atmospheric gap between the Earth and clouds due to $\mathrm{CO}_{2}$ and $\mathrm{H}_{2} \mathrm{O}$ molecules in the frequency range where the optical thickness of the atmosphere is of the order of one.

One can see from the data of Table 3 that the change in the radiative flux $\Delta_{c}$ due to $\mathrm{CO}_{2}$ molecules as a result of doubling the concentration of $\mathrm{CO}_{2}$ molecules is five times larger than the change in the total radiative flux $\Delta$. In climatological models, the Kirchhoff law [50], according to which radiators are simultaneously absorbers, is ignored. Therefore, the change in the radiative flux $\Delta_{c}$ due to $\mathrm{CO}_{2}$ molecules is taken in climatological models instead of the change in the total radiative flux $\Delta$, and the error in the change of the global temperature under these conditions is exceeded by five times. This results from neglecting the absorption of emitted radiative fluxes by water molecules and water microdroplets of clouds by added $\mathrm{CO}_{2}$ molecules [51,52]). This large difference follows also from a general conclusion for a plane gaseous layer with a low temperature gradient [51,52]). Indeed, if we have a layer of a constant temperature and of a high optical thickness, where the emission is created by several components, this layer emits as a blackbody with the gaseous 
temperature. Therefore, a change in the concentration of some optically active component would not lead to the change in the outgoing radiative flux.

A comparison of the results of these evaluations with those of [1] allows one to estimate the accuracy of the change in radiative fluxes, which is estimated as $\sim 10 \%$. The same accuracy corresponds to the derivative of the radiative flux over the concentration of a given component. From these calculations, in the case that the concentration of $\mathrm{CO}_{2}$ molecules varies, while other atmospheric parameters are unvaried, we have the following:

$$
\frac{d J_{\downarrow}}{d \ln c\left(\mathrm{CO}_{2}\right)} \approx 2 \frac{W}{m^{2}}
$$

where $J_{\downarrow}$ is the radiative flux from the atmosphere to the Earth, and $c\left(\mathrm{CO}_{2}\right)$ is the concentration of $\mathrm{CO}_{2}$ molecules.

Along with variations in the concentration of $\mathrm{CO}_{2}$ molecules, other changes take place in the real atmosphere, which influence the global temperature. Let us analyze this change in the real atmosphere on the basis of measurements within the framework of NASA programs. We use below the results of measurements for the concentration $c\left(\mathrm{CO}_{2}\right)$ of carbon dioxide molecules [53,54]. Because the time of residence of a $\mathrm{CO}_{2}$ molecule is large, we take the evolution of the atmospheric concentration of $\mathrm{CO}_{2}$ molecules according to measurements in the Mauna Loa observatory as the global evolution of this quantity. Next, the evolution of the global temperature during the last 150 years is analyzed carefully by the Goddard Institute for Space Studies (GISS) (for example, [55]) within the framework of the NASA program. These results are collected in [1] and are as follows:

$$
\frac{d \ln c\left(\mathrm{CO}_{2}\right)}{d t}=0.006 \mathrm{yr}^{-1}, \frac{d \Delta T}{d t}=0.018 \mathrm{~K} / \mathrm{yr}
$$

One can connect the change in the radiative flux from the atmosphere to the Earth $J_{\downarrow}$ and the change in the global temperature $\Delta T$ through climate sensitivity $S$, according to relation $[18,56]$ :

$$
S=\frac{d \Delta T}{d J_{\downarrow}}
$$

We use the average value of these quantities, which follows from an average of various data and is $S \approx 0.5 \mathrm{~m}^{2} \cdot \mathrm{K} / \mathrm{W}$ [1]. One can estimate the accuracy of this value as $\approx 50 \%$. From this, for the derivation of the radiative flux $J_{\downarrow}$ over the concentration of $\mathrm{CO}_{2}$ molecules $\left(\mathrm{cCO}_{2}\right)$ in the real atmosphere, we have the following:

$$
\frac{d J_{\downarrow}}{d \ln c\left(\mathrm{CO}_{2}\right)} \approx 6 \frac{W}{m^{2}}
$$

We note that in contrast to formula (19) where all atmospheric parameters, except for the concentration of $\mathrm{CO}_{2}$ molecules, are unvaried, formula (22) takes into account other processes that lead to the change in the global temperature. As is seen, the contribution of carbon dioxide in the change in the global temperature for the evolution of the real temperature is approximately $30 \%$.

By analogy with the $\mathrm{CO}_{2}$ case, one can analyze the influence of the change in atmospheric water molecules on the change in the radiative flux from the atmosphere to the Earth. Some results that are analogous to those of Table 3 are given in Table 4. From the data of this table, we have the following:

$$
\frac{d J_{\downarrow}}{d \ln c\left(\mathrm{H}_{2} \mathrm{O}\right)}=7 \frac{\mathrm{W}}{\mathrm{m}^{2}},
$$

where $c\left(\mathrm{H}_{2} \mathrm{O}\right)$ is the concentration of atmospheric water molecules. 
Table 4. Variations in radiative fluxes from the standard atmosphere to the Earth as a change in the concentration of $\mathrm{H}_{2} \mathrm{O}$ molecules. Here, $c\left(\mathrm{H}_{2} \mathrm{O}\right)$ is the contemporary concentration of $\mathrm{H}_{2} \mathrm{O}$ molecules, and $c^{\prime}\left(\mathrm{H}_{2} \mathrm{O}\right)$ is that at a new concentration of water molecules. The radiative fluxes represented are expressed in $\mathrm{W} / \mathrm{m}^{2}$.

\begin{tabular}{ccccc}
\hline$c^{\prime}\left(\mathrm{H}_{\mathbf{2}} \mathrm{O}\right) / c\left(\mathrm{H}_{\mathbf{2}} \mathrm{O}\right)$ & $\boldsymbol{\Delta}_{\boldsymbol{c}}$ & $\boldsymbol{\Delta}_{w}$ & $\boldsymbol{\Delta}_{\boldsymbol{d}}$ & $\boldsymbol{\Delta}$ \\
\hline 0.5 & 3.84 & -15.64 & 6.52 & -4.98 \\
0.7 & 2.05 & -7.94 & 3.20 & -2.53 \\
0.9 & 0.62 & -2.38 & 0.91 & -0.74 \\
1 & 0 & 0 & 0 & 0 \\
1.1 & -0.57 & 2.10 & -0.81 & 0.66 \\
1.5 & -2.52 & 8.86 & -3.36 & 2.78 \\
2 & -4.42 & 15.15 & -5.65 & 4.71 \\
\hline
\end{tabular}

Let us assume that along with an increase in the concentration of $\mathrm{CO}_{2}$ molecules, the evolution of the global temperature of the real atmosphere is determined by the increase in the concentration of $\mathrm{H}_{2} \mathrm{O}$ molecules. Then, water molecules account for the contribution of 2/3 of the change in the global temperature. On the basis of Formula (20), we have the following:

$$
\frac{d \Delta T\left(\mathrm{H}_{2} \mathrm{O}\right)}{d t}=12 \frac{m \mathrm{~K}}{\mathrm{yr}},
$$

where $\Delta T\left(\mathrm{H}_{2} \mathrm{O}\right)$ is the part of the global temperature change which follows from an increase in the concentration of $\mathrm{H}_{2} \mathrm{O}$ molecules. Taking as early $S \approx 0.5 \mathrm{~m}^{2} \cdot \mathrm{K} / \mathrm{W}$, one can find the derivation part of the radiative flux from the atmosphere to the Earth due to $\mathrm{H}_{2} \mathrm{O}$ molecules as follows:

$$
\frac{d J_{\downarrow}\left(\mathrm{H}_{2} \mathrm{O}\right)}{d t}=24 \frac{W}{\mathrm{~m}^{2} \cdot \mathrm{yr}^{\prime}},
$$

From this, it follows the rate of variation for the concentration of the water molecules $c\left(\mathrm{H}_{2} \mathrm{O}\right)$, which can provide this change:

$$
\frac{d \ln c\left(\mathrm{H}_{2} \mathrm{O}\right)}{d t}=0.003 \mathrm{yr}^{-1}
$$

According to this result, the observed rate of an increase in the global temperature may be determined by an increase in the following average number density of water molecules:

$$
\frac{d N\left(\mathrm{H}_{2} \mathrm{O}\right)}{d t}=10^{15} \mathrm{~cm}^{-3} \mathrm{yr}^{-1}
$$

The annual change in the number density is small, compared to the contemporary number density of water molecules, which is equal to $3.4 \times 10^{17} \mathrm{~cm}^{-3}$. Therefore, a real determination of this derivation under contemporary conditions is problematic and requires additional efforts similar to those for the evolution of the global temperature.

It should be noted that the moisture $\eta$ is the measured water parameter in the atmosphere that is given by the following:

$$
\eta=\frac{N\left(\mathrm{H}_{2} \mathrm{O}\right)}{N_{\text {sat }}\left(\mathrm{H}_{2} \mathrm{O}\right)}=\frac{c\left(\mathrm{H}_{2} \mathrm{O}\right)}{c_{\text {sat }}\left(\mathrm{H}_{2} \mathrm{O}\right)},
$$

where $\mathrm{N}_{\text {sat }}\left(\mathrm{H}_{2} \mathrm{O}\right)$ is the number density of water molecules at the saturated vapor pressure for a given temperature, $c\left(\mathrm{H}_{2} \mathrm{O}\right)$ is a current concentration of water molecules in atmospheric air, and $c_{\text {sat }}\left(\mathrm{H}_{2} \mathrm{O}\right)$ is its concentration for the saturated vapor pressure at the air temperature. The contemporary value of the atmosphere moisture is $\eta \approx 80 \%$ [57].

Let us determine the rate of the moisture variation due to the temperature change. Because the amount of atmospheric water is small compared to that at the Earth's surface, we have, from an equilibrium between the atmospheric and surface water, the following: 


$$
c_{\text {sat }}\left(H_{2} \mathrm{O}\right) \sim \exp \left(-\frac{E_{a}}{T}\right),
$$

where $E_{a}=0.43 \mathrm{eV}[58]$ is the binding energy for a water molecule with its bulk liquid. From this, for the rate of an increase in the atmosphere capacity with respect to water molecules due to a temperature increase, we have the following:

$$
\frac{d c_{s a t}\left(\mathrm{H}_{2} \mathrm{O}\right)}{d t}=\frac{E_{a}}{T^{2}} \cdot \frac{d T}{d \Delta t} \approx 0.001 \mathrm{yr}^{-1}
$$

The process of growth of the atmospheric moisture will be stopped through a time $t_{e v}$, according to the following equation:

$$
t_{e v}=\frac{1-c\left(\mathrm{H}_{2} \mathrm{O}\right)}{c\left(\mathrm{H}_{2} \mathrm{O}\right)-c_{\text {sat }}\left(\mathrm{H}_{2} \mathrm{O}\right)} \approx 100 \mathrm{yr}
$$

From this, it follows that $t_{e v} \approx 100 \mathrm{yr}$, i.e., this time is sufficiently large to check this mechanism of the Earth's heating.

\section{Conclusions}

The goal of this paper is to apply the improved code for the evaluation of the radiative fluxes from the atmosphere to the Earth on the basis of the model of [1]. In these evaluations, we use the range of frequencies up to $2600 \mathrm{~cm}^{-1}$ in contrast to the previous calculations [1], where this range was restricted by $1200 \mathrm{~cm}^{-1}$. Besides this difference, we use now various versions of the energetic balance of the Earth and its atmosphere (see Table 1), and the difference in radiative parameters due to various versions of the Earth's energetic balance may be considered an error of the results. Nevertheless, the cloud boundary altitude $h_{c l}$, as one of basic parameters of the model under consideration, according to [1], is $h_{c l}=$ $4.3 \mathrm{~km}$, whereas from Table 1 , the average altitude of the cloud boundary is $h_{c l}=4.6 \mathrm{~km}$, i.e., these values coincide within the accuracy of these evaluations.

Because carbon dioxide molecules do not absorb in the additional spectrum range between $1200 \mathrm{~cm}^{-1}$ and $2600 \mathrm{~cm}^{-1}$, the radiative parameters due to $\mathrm{CO}_{2}$ molecules are close in these evaluations and in the previous one. In particular, the variation in radiative fluxes as a result of the change in the carbon dioxide amount in the atmosphere for these calculations are close. In this evaluation as well as previous evaluations, we have a contradiction with the results of climatological models in the analysis of the Earth's greenhouse effect, according to which the increase in the global temperature differs by five times. We show [51,52], so the large difference results from ignoring, in climatological models, the Kirchhoff law [50], according to which radiators are simultaneously the absorbers. In this case, we take the change in the radiative flux created by $\mathrm{CO}_{2}$ molecules as the change of the total radiative flux.

Note the restrictions by the frequency range up to $1200 \mathrm{~cm}^{-1}$ in the previous calculations [1]; we thus assume that the atmosphere is transparent for larger frequencies, and the emission at larger frequencies is determined by clouds. However, according to the HITRAN data bank, water molecules absorb effectively in the enlarged frequency range. As a result, the derivative (22) is larger than that according to [1]. We proved early (for example, [1]) that atmospheric $\mathrm{CO}_{2}$ molecules are not the main radiator of the atmosphere. From these evaluations, it follows that water molecules in the atmosphere may be responsible for the observed heating of the Earth.

Author Contributions: Writing—original draft, B.M.S. and D.A.Z. All authors have read and agreed to the published version of the manuscript.

Funding: This research received no external funding.

Conflicts of Interest: The authors declare no conflict of interest. 


\section{References}

1. Smirnov, B.M. Transport of Infrared Atmospheric Radiation; De Gruyter: Berlin, Germany, 2020.

2. Goody, R.M. Atmospheric Radiation: Theoretical Basis; Oxford University Press: London, UK, 1964.

3. Goody, R.M.; Yung, Y.L. Principles of Atmospheric Physics and Chemistry; Oxford University Press: New York, NY, USA, 1995.

4. U.S. Government Printing Office. U.S. Standard Atmosphere; U.S. Government Printing Office: Washington, DC, USA, 1976.

5. Center for Astrophysics. Available online: https://www.cfa.harvard.edu/ (accessed on 4 August 2021).

6. HITRAN on the Web. Available online: http:/ /www.hitran.iao.ru/home (accessed on 4 August 2021).

7. HITRANonline-Documentation: Units and Definitions. Available online: http://www.hitran.org/links/docs/definitions-andunits / (accessed on 4 August 2021).

8. Simeckova, M.; Jacquemart, D.; Rothman, L.S.; Gamache, R.R.; Goldman, A. Einstein A-coefficients and statistical weights for molecular absorption transitions in the HITRAN database. J. Quant. Spectrosc. Radiat. Transf. 2006, 98, 130. [CrossRef]

9. Houghton, J.T. The Physics of Atmospheres; Cambridge University Press: Cambridge, UK, 1977.

10. Iribarne, J.V.; Cho, H.P. Atmospheric Physics; Reidel Publ.: Dordrecht, The Netherlands, 1980.

11. Fleagle, R.G.; Businger, J.A. Introduction to Atmospheric Physics; Academic Press: San Diego, CA, USA, 1980.

12. Salby, M.L. Fundamentals of Atmospheric Physics; Academic Press: San Diego, CA, USA, 1996.

13. Seinfeld, J.H.; Pandis, S.N. Atmospheric Chemistry and Physics; Wiley: New York, NY, USA, 1998.

14. Andrews, D.G. An Introduction to Atmospheric Physics; Cambridge University Press: Cambridge, UK, 2000.

15. Seinfeld, J.H.; Pandis, S.N. Atmospheric Chemistry and Physics; Wiley: Hoboken, NJ, USA, 2006.

16. Walace, J.M.; Hobbs, R. Atmospheric Science. An Introductory Survey; Elsevier: Amsterdam, The Netherlands, 2006.

17. Ambaum, M.H.P. Thermal Physics of the Atmosphere; Wiley-Blackwell: Oxford, UK, 2010.

18. Salby, M.L. Physics of the Atmosphere and Climate; Cambridge University Press: Cambridge, UK, 2012.

19. Lagzi, I.; Meszaros, R.; Gelybo, G.; Leelossy, A. Atmospheric Chemistry; Institute of Geography and Earth Science: Budapest, Germany, 2013.

20. Caballero, R. Physics of the Atmosphere; IOP Publishing: Bristol, UK, 2014.

21. Smirnov, B.M. Microphysics of Atmospheric Phenomena; Springer Atmospheric Series; Springer: Cham, Switzerland, 2017.

22. Visconti, G. Fundamentals of Physics and Chemistry of the Atmosphere; Springer Nature: Cham, Switzerland, 2017.

23. Reif, F. Statistical and Thermal Physics; McGrow Hill: Boston, MA, USA, 1965.

24. Landau, L.D.; Lifshitz, E.M. Statistical Physics; Pergamon Press: Oxford, UK, 1980; Volume 1.

25. Zel'dovich, B.Y.; Raizer, P.Y. Physics of Shock Waves and High-Temperature Hydrodynamic Phenomena; Acad. Press: New York, NY, USA, 1966.

26. Smirnov, B.M. Physics of Weakly Ionized Gas; Nauka: Moscow, Russia, 1972. (In Russian)

27. Smirnov, B.M. Radiation of Gas Layer over Hot Surface. J. Exp. Theor. Phys. 2018, 126, 446. [CrossRef]

28. Smirnov, B.M. Physics of Weakly Ionized Gases; Mir: Moscow, Russia, 1980.

29. Smirnov, B.M. Physics of Ionized Gases; Wiley: New York, NY, USA, 2001.

30. Smirnov, B.M. Global Atmospheric Phenomena Involving Water; Springer Atmospheric Series; Springer: Cham, Switzerland, 2020.

31. Wien, W. Ueber die Energievertheilung im Emissionsspectrum eines schwarzen Körpers. Wied. Ann. Phys. Chem. 1896, 58, 662. [CrossRef]

32. United States Committee for the Global Atmospheric Research Program. Understanding Climate Change; Nat. Acad. Science: Washington, DC, USA, 1975.

33. Smirnov, B.M. Introduction to Plasma Physics; Mir: Moscow, Russia, 1977.

34. Smirnov, B.M. Energetics of Atmosphere; Phys. Series N3; Znanie: Moscow, Russia, 1979. (In Russian)

35. Ramanathan, V. Atmospheric General Circulation and its Low Frequency Variance: Radiative Influences. J. Meteorol. Soc. Jpn. 1987, 65, 151. [CrossRef]

36. Ramanathan, V. The role of earth radiation budget studies in climate and general circulation research. J. Geophys. Res. 1987, 92, 4075. [CrossRef]

37. Ramanathan, V. The greenhouse theory of climate change: A test by an inadvertent global experiment. Science 1988, $240,293$. [CrossRef] [PubMed]

38. Raval, A.; Ramanathan, V. Observational determination of the greenhouse effect. Nature 1989, 342, 758. [CrossRef]

39. Ramanathan, V.; Cess, R.D.; Harrison, E.F.; Minnis, P.; Barkstrom, B.R.; Ahmad, E.; Hartmann, D. Cloud-radiative forcing and climate: Results from the Earth Radiation Budget Experiment. Science 1989, 243, 57. [CrossRef] [PubMed]

40. Ramanathan, V.; Harrison, E.F.; Barkstrom, B.R. Climate and the Earth's Radiation Budget. Phys. Today 1989, 42, 22. [CrossRef]

41. Kiehl, J.T.; Trenberth, K.E. Earth's Annual Global Mean Energy Budget. Bull. Am. Meteorol. Soc. 1997, 78, 197. [CrossRef]

42. Trenberth, K.E.; Fasullo, J.T.; Kiehl, J.T. Earth's Global Energy Budget. Bull. Am. Meteorol. Soc. 2009, 90, 311. [CrossRef]

43. Trenberth, K.E.; Fasullo, J.T. Tracking Earth's energy: From El Niño to global warming. Surf. Geophys. 2012, 33, 413. [CrossRef]

44. Fasullo, J.T.; Trenberth, K.E. A less cloudy future: The role of subtropical subsidence in climate sensitivity. Science 2012, $338,792$. [CrossRef] [PubMed]

45. Stephens, G.L.; Li, J.; Wild, M.; Clayson, C.A.; Loeb, N.; Kato, S.; L'ecuyer, T.; Stackhouse, P.W.; Lebsock, M.; Andrews, T. An update on Earth's energy balance in light of the latest global observations. Nat. Geosci. 2012, 5, 691. [CrossRef] 
46. Wild, M.; Folini, D.; Schär, C.; Loeb, N.; Dutton, E.G.; König-Langlo, G. The global energy balance from a surface perspective. Clim. Dyn. 2013, 40, 3107. [CrossRef]

47. Trends in Atmospheric Methane. Available online: https://www.esrl.noaa.gov/gmd/ccgg/trends-ch4/ (accessed on 4 August 2021).

48. Machida, T.; Nakazawa, T.; Fujii, Y.; Aoki, S.; Watanabe, O. Increase in the atmospheric nitrous oxide concentration during the last 250 years. Geophys. Res. Lett. 1995, 22, 2921. [CrossRef]

49. Climate-Sensitivity. Available online: https://en.wikipedia.org/wiki/Climate-sensitivity (accessed on 4 August 2021).

50. Kirchhoff, G.; Bunsen, R. Zusammenhang von emission und absorption von Licht und Wärme. Ann. Phys. Chem. 1860, $109,275$. [CrossRef]

51. Smirnov, B.M. Interaction of radiative molecules in gas emission. Int. Rev. At. Mol. Phys. 2019, 10, 39.

52. Smirnov, B.M. Atmospheric carbon dioxide and climate. J. Atmos. Sci. Res. 2019, 2, N4. [CrossRef]

53. Mauna-Loa-Observatory. Available online: https://en.wikipedia.org/wiki/Mauna-Loa-Observatory (accessed on 4 August 2021).

54. Trends in Atmospheric Carbon Dioxide. Available online: https://www.ersl.noaa.gov/gmd/cggg/trends (accessed on 4 August 2021).

55. Hansen, J.; Sato, M.; Ruedy, R. Available online: http:/ / www.columbia.edu/ jeh1/mailing/2016/20160120-Temperature2015 (accessed on 4 August 2021).

56. Rohling, E.J.; Sluijs, A.; Dijkstra, H.A.; van de Wal, R.S.W.; von der Heydt, A.S.; Bijl, P.K.; Zeebe, R. Making sense of palaeoclimate sensitivity. Nature 2012, 491, 683.

57. Moisture. Available online: https:/ / en.wikipedia.org/wiki/Moisture (accessed on 4 August 2021).

58. Lide, D.R. (Ed.) Handbook of Chemistry and Physics, 84th ed.; CRC Press: London, UK, 2003. 